\title{
Nonclassical focal nodular hyperplasia of the liver in a chronic alcoholic: A diagnostic dilemma on FNAC
}

\author{
Pai R, Khadilkar UN, Diaz E, Prabhu S, Gupta S \\ Kasturba Medical College, Mangalore, Karnataka, India
}

\begin{abstract}
In a 49 year old male, a chronic alcoholic with hepatomegaly, a subcapsular nodular lesion was detected in the right lobe of the liver. On fine needle aspiration cytology, hepatocellular carcinoma was considered. Excision of the lesion showed features of nonclassical focal nodular hyperplasia with large cell dysplasia that caused the diagnostic dilemma on cytology.
\end{abstract}

Key words: Focal nodular hyperplasia, Large cell dysplasia/atypia, Benign liver mass, Fine needle aspiration cytology

Cocal nodular hyperplasia (FNH) of the liver is a well described entity in its classical form. The nonclassical forms include telangiectatic FNH, mixed hyperplastic and adenomatous form, and FNH with cytologic atypia ${ }^{1}$. The atypical hepatocytes have enlarged nuclei with irregular nuclear contour, hyperchromasia, coarse granular chromatin and conspicuous nucleoli in FNH with cytologic atypia ${ }^{1}$. Fine needle aspiration cytology (FNAC) of FNH with cytologic atypia has to be distinguished from hepatocellular carcinoma (HCC) both well-differentiated, and fibrolamellar type. Ancillary studies are of value in the differential diagnosis.

\section{Case Report}

A 49 year old male presented with generalized weakness and vomiting since one month. He had two to three episodes of nonbilious vomiting every second or third day. It was not coffee ground in colour. There was history of epigastric pain, loss of weight and loss of appetite. Patient was a chronic smoker and alcoholic for the past 20 years consuming about $100 \mathrm{ml}$ of alcohol per day. There was no history of jaundice in the past.

On per abdominal examination, liver was enlarged $4 \mathrm{~cm}$ below the right costal margin and was tender. There was no splenomegaly. All other systems were within normal limits.

The following investigations were done. Liver function tests were normal. Hepatitis B surface antigen and Hepatitis C virus antibody were negative. Stool for occult blood was negative. Haemoglobin, bleeding time, clotting time, prothrombin time and platelet count were within normal limits. Ultrasonography showed enlarged liver with fatty and inhomogenous echotexture. A solitary, irregular solid hypoechoic lesion was detected subcapsularly on the anterior surface of right lobe of the liver measuring $2.6 \times 1.4 \mathrm{~cm}$ in size. It was sampled using a fine needle for cytological evaluation.

Cytology findings: The smears were moderately cellular and showed hepatocyte groups with fatty change and large syncytitial fragments with traversing capillaries composed of large hepatocytes with pleomorphic hyperchromatic nuclei and prominent nucleoli (fig 1). Intranuclear cytoplasmic inclusions were evident. An occasional group was rounded and bordered by a discontinuous endothelial lining. No bare atypical nuclei were seen. No ductal epithelial cells were seen. A diagnosis of $\mathrm{HCC}$ was considered and serum alpha-foetoprotein was requested, and was found to be normal.

Due to uncertainity of the diagnosis, excision of the mass was done and sent for histopathological study. Incidentally, a small gray-white nodule was found in the left lobe of the liver which was also removed.

Gross pathology: An irregular tan coloured liver tissue with subcapsular nodular mass was received totally measuring $3 \times 2 \times 1 \mathrm{cms}$. Cut surface showed a sharply demarcated gray-white focal cirrhosis-like multinodular

Correspondence

Dr. Radha R. Pai

Additional Professor,

Department of Pathology,

Kasturba Medical College,

Mangalore - 575001, Karnataka, India

E-mail: pairadharam@yahoo.co.in 
lesion measuring $2.5 \mathrm{~cm}$ in its maximum dimension (fig 2 ). The left lobe lesion consisted of a gray-white small nodule $0.75 \mathrm{~cm}$ in size.

Histopathology: The nodules were made up of enlarged hepatocytes arranged in two cell thick trabeculae. The nuclei were hyperchromatic with prominent nucleoli. Fatty change and intracytoplasmic Mallory hyaline was observed. Intranuclear cytoplasmic inclusions were prominent. The nodules were encircled by fibrous septae which were infiltrated by lymphocytes (fig 3).

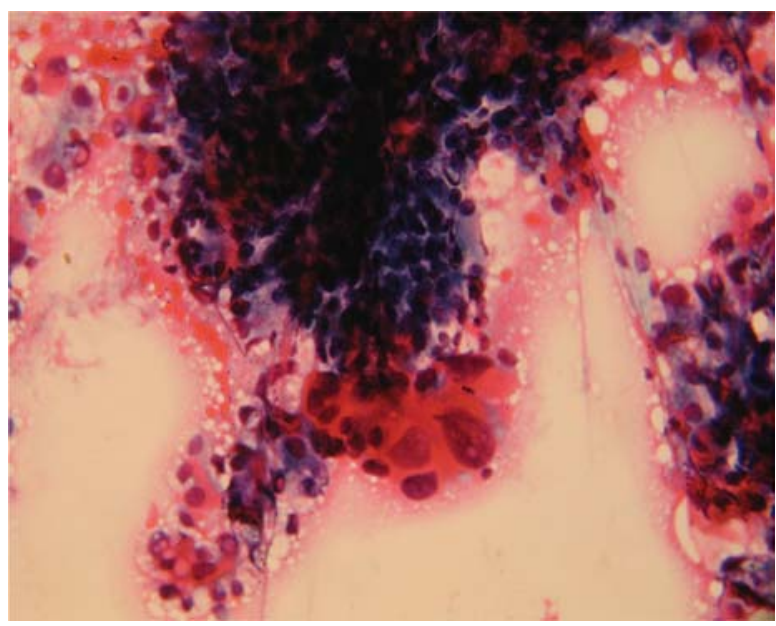

Fig 1: Cytology smear showing jagged syncytial groups of hyperchromatic pleomorphic hepatocytes. The cell spread is poor and there are no atypical bare nuclei in the background (Pap stain $\times 400$ )
There was no bile duct proliferation. However, abortive ductule formation was seen at the interface between hepatocytes and the fibrous region. Thick-walled blood vessels with fibromuscular hyperplasia were seen in the fibrous septae. The reticulin stain showed a regular reticulin framework. The nodule from left lobe of the liver showed features of bile duct adenoma.

A final diagnosis of nonclassical $\mathrm{FNH}$ of right lobe of the liver with large cell dysplasia and concomitant bile duct adenoma of the left lobe was made.

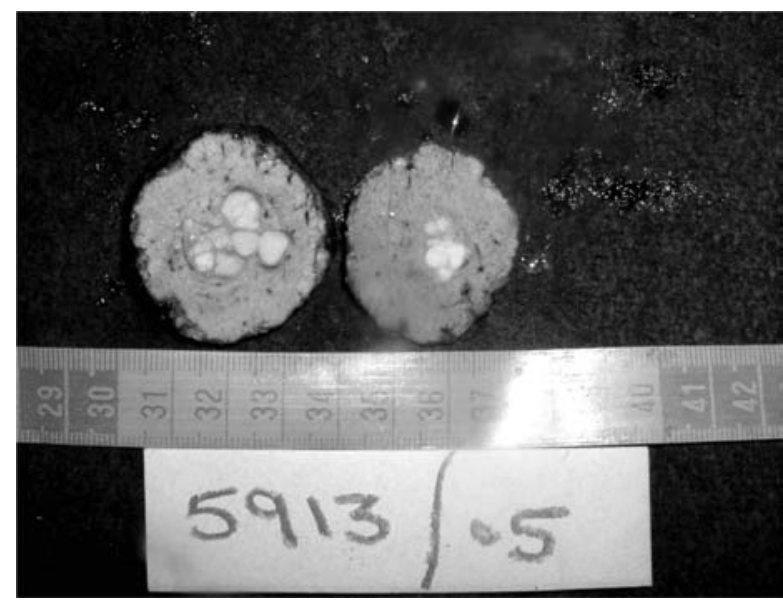

Fig 2: The excised liver tissue showing multinodular, focal cirrhosis-like lesion

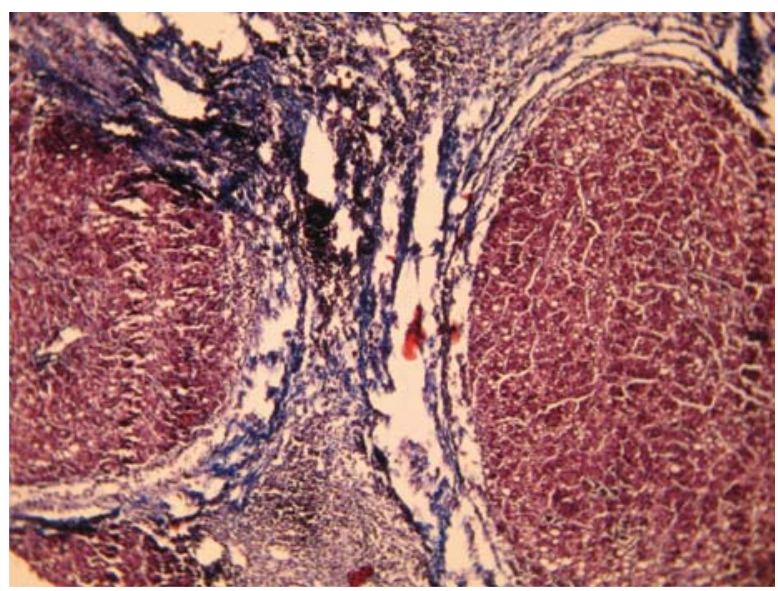

Fig 3: Histopathology showing fibrous septae with lymphocytic infiltrate encircling nodules composed of thin trabeculae of hepatocytes with fatty change and nuclear atypia (Masson trichrome stain $\times 100$ ) 


\section{Discussion}

FNH of the liver can be seen at any age, however most cases are seen during third to fifth decades of life. It shows a female predominance ${ }^{1,2}$. In males, it is particularly associated with alcohol abuse ${ }^{2}$. Atypia of large cell type is rarely described in $\mathrm{FNH}^{1}$. Two cases of FNH with cytologic features sufficiently atypical to warrant a diagnosis of carcinoma is documented. However, neither of these cases metastasized ${ }^{3}$. FNH with cytologic atypia and associated alcoholic hyaline is reported ${ }^{4}$. In a comprehensive pathologic study of FNH, among 305 lesions, atypia was found in only eight lesions. Along with atypia, alcoholic hyaline was seen in four cases ${ }^{1}$. In a series of five cases of FNH studied on FNAC none showed atypia ${ }^{5}$.

In the present case FNAC of FNH of the liver with large cell dysplasia was interpreted as HCC. Flat clusters of hepatocytes with irregular jagged edges and no peripheral endothelial wrapping are characteristic of a benign lesion. The presence of ductal epithelial cells favour a benign lesion, however its absence does not exclude FNH. The cytologic features more strongly associated with HCC are three-dimensional cohesive, rounded, smooth edged clusters and trabeculae with peripheral wrapping of endothelial cells, well defined capillaries traversing tissue fragments, increased nuclear/cytoplasmic ratio, irregular nuclear contour, and atypical bare nuclei ${ }^{6,7}$. Focal transgression of capillaries can be seen in benign lesions. Nuclear atypia led to a suspicion of HCC in the present case. However, on review the cell spread was poor. Gross inspection of the smear gives an important clue to the diagnosis. Poorly spread rigid tissue cores are seen in benign lesions versus fine granularlity of the smear in HCC. The smear characteristic correlates with their reticulin status on histology ${ }^{8}$. There were no atypical bare nuclei, one of the most important feature of $\mathrm{HCC}^{6,7}$. Also the architectural features were not supportive of a diagnosis of HCC. The cell groups were jagged, the trabeculae were thin and there was no significant smooth rounding up of the cell groups. Silver impregnation stain on cytology smear is useful to distinguish abnormal growth of regenerating hepatocytes from HCC. Reticulin framework is present in hepatocellular adenoma, $\mathrm{FNH}$ and cirrhotic nodules, in contrast to $\mathrm{HCC}$ which shows scarce or absent reticulin 9 . In this case reticulin stain was not done on cytology smear. On histopathology the reticulin framework was normal. Fibrolamellar HCC resembles FNH grossly, however, cytologically there is a discohesive pattern in fibrolamellar HCC composed of large polygonal cells with eosinophilic granular cytoplasm with distinct borders resembling the Hurthle cells in thyroid aspirates. They have a central round nuclei displaying a huge nucleolus. Intracytoplasmic pale bodies and hyaline inclusions are additional helpful features. Trabecular arrangement is not seen in fibrolamellar HCC. Fragments of fibrous lamellae may be seen as in FNH, but the cytologic features are distinctive $^{10}$.

\section{Conclusion}

To conclude, atypia in FNH may be mistaken for $\mathrm{HCC}$ on FNAC. Close attention should be paid to architectural and cytological features. Ancillary studies like serum alpha-foeto protein and reticulin stain on cytology/cell block preparation are of value in the differential diagnosis. To the best of our knowledge, such a case of nonclassical FNH with clinical and cytohistopathological correlation is not recorded in the literature. The association of nonclassical FNH with bile duct adenoma may be just an incidental finding.

\section{References}

1. Nguyen BN, Fléjou JF, Terris B, Belghiti J, Degott C. Focal Nodular Hyperplasia of the Liver A Comprehensive Pathologic Study of 305 Lesions and Recognition of New Histologic Forms. Am J Surg Pathol 1999;23:1441-54.

2. Desmet VJ, Rosai J. Liver. In: Rosai J, editor. Rosai and Ackerman's Surgical Pathology. $9^{\text {th }}$ ed. India: Elsevier Inc; 2004. P. 917 - 1003.

3. Christopherson W, Mays T and Barrows G. A clinicopathologic study of steroid related liver tumors. Am J Surg Pathol 1977;1:31 - 71.

4. Wetzel WJ, and Alexander RW. Focal nodular hyperplasia of the liver with alcoholic hyaline bodies and cytologic atypia. Cancer 1979;44:1322 - 6 .

5. Ruschenburg I, Droese M. Fine needle aspiration cytology of focal nodular hyperplasia of the liver. Acta Cytol 1989;33:857 - 60.

6. de Boer WB, Segal A, Frost FA, Sterrett GF. Cytodiagnosis of well differentiated hepatocellular carcinoma: can indeterminate diagnosis be reduced ? Cancer 1999;87:270 -7.

7. Granados R, Aramburu JA, Murillo N, Camarmo E, de la Cal MA, and Fernandez-Segoviano P. Fine-Needle Aspiration Biopsy of Liver Masses: Diagnostic Value and Reproducibility of Cytologic Criteria. Diagn. Cytopathol. 2001;25:365-75.

8. Yang GC, Yang GY, Tao LC. Distinguishing well-differentiated hepatocellular carcinoma from benign liver by the physical features of fine-needle aspirates. Mod Pathol 2004;17:798 -802 .

9. Gagliano EF. Reticulin Stain in the Fine Needle Aspiration Differential Diagnosis of Liver Nodules. Acta Cytol 1995;39:596-8.

10. Pérez-Guillermo M, Masgrau NA, GarciaSolano J, Sola-Pérez J, de Agustin y de Agustin P. Cytologic aspects of fibrolamellar hepatocellular carcinoma in fine-needle aspirates. Diagn.Cytopathol 1999;21:180-7. 